\title{
Exploring person-centred care in relation to resource utilization, resident quality of life and staff job strain - findings from the SWENIS study
}

\author{
Anders Sköldunger ${ }^{1,2^{*}}$ (D), Per-Olof Sandman ${ }^{1,3}$ and Annica Backman ${ }^{1}$
}

\begin{abstract}
Background: A critical challenge facing elderly care systems throughout the world is to meet the complex care needs of a growing population of older persons. Although person-centred care has been advocated as the "gold standard" and a key component of high-quality care, the significance of care utilisation in person-centred units as well as the impact of person-centred care on resident quality of life and staff job strain in nursing home care has yet to be explored.

The aim of this study was to explore person-centred care and its association to resource use, resident quality of life, and staff job strain.

Design: A cross-sectional national survey.

Methods: Data on 4831 residents and 3605 staff were collected by staff working in nursing homes in 35 randomly selected Swedish municipalities in 2014. Descriptive statistics and regression modelling were used to explore associations between person-centred care and resource use, resident quality of life, and staff job strain.

Results: No association was found between person-centred care and resource use. Person-centred care was positively associated with resident quality of life and was negatively associated with staff perception of job strain.

Conclusion: Person-centred care does not increase resource utilisation in nursing homes, but beneficially impacts resident quality of life and alleviates the care burden in terms job strain among staff.
\end{abstract}

Keywords: Person-centred care, Resource utilisation, Quality of life, Job strain

\section{Background}

Worldwide, a larger proportion of people are reaching old age as life expectancy continues to increase [1]. The rising number of older persons is leading to increased demands for the provision of nursing home care, which in turn poses great strain on public resources in Sweden,

\footnotetext{
* Correspondence: Anders.skoldunger@umu.se

'Department of Nursing, Umeå University, Vårdvetarhuset, 90187 Umeå, Sweden

${ }^{2}$ Division of Neurogeriatrics, Karolinska Institutet, Huddinge, Sweden Full list of author information is available at the end of the article
}

as well as globally [2, 3]. Nursing homes have a high prevalence of persons with cognitive impairment and dementia (50-84\%) [4-6], and the major cost drivers in dementia care are costs of long-term institutional care in nursing homes and the costs of informal care [7].

The number of beds in municipal elderly care in Sweden has decreased from 120,000 to 90,000 between 2000 and 2010 [8] even though the proportion of older persons continues to grow. Swedish elderly care organisations comply with the Scandinavian model of publicly funded and essentially publicly produced care services,

C C The Author(s). 2020 Open Access This article is licensed under a Creative Commons Attribution 4.0 International License, which permits use, sharing, adaptation, distribution and reproduction in any medium or format, as long as you give appropriate credit to the original author(s) and the source, provide a link to the Creative Commons licence, and indicate if changes were made. The images or other third party material in this article are included in the article's Creative Commons licence, unless indicated otherwise in a credit line to the material. If material is not included in the article's Creative Commons licence and your intended use is not permitted by statutory regulation or exceeds the permitted use, you will need to obtain permission directly from the copyright holder. To view a copy of this licence, visit http://creativecommons.org/licenses/by/4.0/ The Creative Commons Public Domain Dedication waiver (http://creativecommons.org/publicdomain/zero/1.0/) applies to the data made available in this article, unless otherwise stated in a credit line to the data. 
where the national policy specifies that older persons should be supported in living independently with a high quality of life and that older persons in need of care are entitled to high-quality care [9]. The Swedish elderly care system can be described as formalised care services that are regulated by Swedish law and are financed and in most cases provided by the public sector through municipal taxes and government grants. The total cost of elderly care in Sweden was SEK 95.9 billion, (approx. EUR 10.7 billion) in 2010, and of this about 3\% of the cost was financed by patient charges [8]. New regulations and recommendations have emerged with expectations on the elderly care organisations to operate more efficiently while providing high care quality based on a person-centred philosophy [10-12]. Person-centred services are currently recommended as a global strategy to address the diverse and expanding care needs of an aging population [12].

The concept of person-centred care (PCC) has progressed significantly in research and practice and has dominated the research field over the last 20 years and is now considered the gold standard for the care of older people [13-16]. PCC is focused on moving beyond illnesses and dysfunction in a person and seeks to maintain personhood despite illness by using personal experiences to individualise the person's care and their environment. PCC also involves creating a supportive social environment, prioritising relationships, seeing behaviour from the person's perspective, involving relatives in care, and offering shared decision-making [13, 17-19].

PCC is expected to lead to improved well-being and reduced ill health $[13,17,18,20]$, and previous studies have shown that residents might benefit from this approach in terms of reduced agitation [21, 22]. However, only a few studies have explored PCC in relation to quality of life, and among the few studies that exist the findings are inconclusive. PCC has been associated with higher resident quality of life [23, 24], and the same was true in a person-centred intervention study [21]. However, contradictory findings have also been reported where a randomised controlled trial comparing PCC and "ordinary care" did not show any significant change in terms of quality of life among residents [25], nor did PCC interventions, the creation of more person-centred environments, or combinations of the two interventions $[26,27]$. A systematic review with purpose to determine the effectiveness of organizational-level person-centred care for people living with dementia in relation to their quality of life showed no significant improvement in quality of life scores with person-centred care (intervention group), compared with usual care (control group). However, a significant effect in the quality of life score could be found within the person-centred care group (intervention group) [28]. This indicates that the findings in this research area are inconclusive and studies exploring how PCC is related to resident quality of life is still needed.

Given the continued worldwide societal costs of care due to aging populations [29] and PCC being advocated as a global strategy to address the diverse range of emerging care needs [12], it seems highly relevant to explore the relation between PCC and resource use. However, this has only been sparsely evaluated before, and among the few studies that exist, PCC has been associated with increased resource use [30], but also with better time efficiency [31, 32]. Implementing person-centred interventions has also been associated with increased costs related to staff education and training during the intervention phase. However, implementation costs of the training programme for PCC were lower than for dementia-care mapping, indicating that PCC might be a more cost effective care model, at least in the implementation phase [22]. Also, if hypothesising that PCC increases resource use (i.e. it increases the direct care hours provided to a resident), this might have an immediate effect on the level of job demands for staff working conditions under prevailing fiscal restraints. The combination of high job demands and low job control in the work environment is postulated to predict job strain [33]. Because elderly care staff are known to have a challenging and demanding job in terms of job strain, [34-39] and because they are exposed to increased risk for adverse health effects [40-43], it seems relevant to explore the association between PCC and resource use. Job strain is also a precursor to burnout, a related psychological syndrome of emotional exhaustion, depersonalisation, and reduced personal accomplishment. Burnout develops as a response to prolonged work stressors when the work demands exceed the capacity of the individual to deal with them [44]. Various person-centred interventions have reported that PCC might reduce staff exhaustion and burnout [45-47], thus highligting the significance for staff health to work in a person-centred manner. It has also been suggested that addressing staff stress and strain are an important focus when striving to improve PCC [48]. This is supported by a recent Swedish study by Sjögren et al. [49] that showed that higher levels of job strain are related to lower levels of PCC, indicating that perceived job strain might also impact the provision of PCC. Based on this, it seems important to explore how job strain is related to PCC in everyday practice, especially given the major impact this might have on staff and resident health in nursing home care. Thus, the presence of strain might hamper staff efforts to address PCC as the philosophy of care. To summarise, PCC has been advocated as the "gold standard" and a key component of high quality of care and has been advocated as a global strategy to address the diverse range of emerging care needs. However, the putative disparities in resource utilisation in person-centred vs. 
less person-centred units and the impact of PCC on resident quality of life and staff job strain in nursing home care has yet to be explored. Thus, the aim of this work was to explore PCC and its association with resource use, resident quality of life, and staff job strain.

\section{Methods}

\section{Design}

The Swedish National Inventory of Care and Health in Residential Aged Care (SWENIS) is a large, ongoing longitudinal study with explorative design conducted within the Umeå Aging and Health Research programme [45] and this study was based on SWENIS baseline data. Ethical approval for this study was obtained from the Regional Ethical Review Board in Umeå (Dnr 2013-269-31).

\section{Sampling and data collection}

In Sweden a municipality is an administrative unit which is responsible for the community service including among other things schools, social care and care for the elderly. Out of 290 municipalities in Sweden, 60 municipalities were randomly selected and invited to participate, and 35 agreed to participate. The randomisation was done by letting a computer randomly select 60 of 290 municipalities. Thereafter, the managers in the nursing homes within these municipalities were contacted by telephone, inviting the nursing home to participate. Nursing homes which accepted the invitation got surveys sent to the nursing home, both to staff and to residents by mail. The data for this study were collected through two different surveys: (a) a self-reporting staff survey comprising demographic variables and established questionnaires for assessing perceived PCC (Personcentred Care Assessment Tool (P-CAT)) and job strain (The Swedish Demand-Control-Support Questionnaire (DCSQ)) and (b) a residents survey giving data on resident characteristics, health-related quality of life, and functional and cognitive status. Assessments of residents were performed by the staff member who knew each resident best (proxy rating). A total of 5423 staff surveys were distributed, and 3605 were returned (response rate 66.5\%) from 169 nursing homes. Of 6902 resident surveys that were sent out, 4831 were returned (response rate 70\%) from 172 nursing homes. The data collection took place from November 2013 to September 2014.

\section{Study context}

In Sweden, there are approximately 2300 nursing homes with approximately 82,000 residents [46]. Swedish nursing homes are defined as housing for the elderly aged over 65 years who are no longer able to live at home due to extensive personal care needs and/or cognitive impairment [46]. Participating units included both special care units for persons with dementia (31\%) and general units caring for older people (69\%), and the number of beds in the facilities varied between 7 and 128 beds (median 38 beds). Most of the nursing homes in this sample (93.5\%) were publically managed, and the remaining $6.5 \%$ were run by private providers.

\section{Study variables \\ Demographic variables}

Demographic data included self-reported data on staff characteristics (i.e. sex, age, qualifications, work experience, and shift work) and proxy-rated data on resident characteristics (i.e. sex, age). An adapted version of the Katz activities of daily living was used to assess resident functional ability [50]. It measures the ability to manage ADL independently in six domains: bathing, dressing, transferring, toileting, eating, and continence. The modified version contained, for each domain, dichotomous scores, where functional dependency was scored " 0 " and fully functional independency was scored " 1 " which results in a total score of 0 to 6 points. Higher score indicate greater independence. Cognitive status was assessed using a scale developed by Gottfries and Gottfries (1968) consisting of 27 items regarding ability to orientate. Statements are answered with a "yes" [1] or "no" (0) resulting in a possible score of 0 to 27 where a higher score indicate better cognitive status, and scores $<24$ indicate cognitive impairment [51].

\section{Person-centred care assessment tool (P-CAT)}

The P-CAT is a self-reported instrument $[52,53]$ used to assess to which extent the staff perceive the care provided to be person-centred. The Swedish version is a five-point Likert-type scale including 13 items $(1=$ disagree completely; $5=$ agree completely). A total score can be calculated with a possible range of 13-65. A mean score per elderly care unit was calculated, and if a unit was missing data a facility mean was imputed for that unit. Higher scores indicated higher levels of PCC.

\section{The Swedish demand-control-support questionnaire (DCSQ)}

Two subscales of the DCSQ were used to measure the extent to which staff experience job strain. The used subscales was self-reported psychological demands and decision latitude (control) from the DCSQ [33]. The subscales consist of a four-point Likert-type scale where staff are asked to rate their perception of their job strain $(1=$ no, never; $4=$ yes, often). The psychological demands consist of five items and decision latitude of six items. The subscales were used to calculate the dependent continuous variable of job strain by dividing the sum of psychological demands by the sum of the decision latitude (control) (cf. 39). The job strain index has a range of $0.21-3.33$, with a higher value indicating greater strain [39]. 


\section{Resource utilization in dementia (RUD)}

Staff time for caregiving was measured by staff by using the RUD instrument [54], which is a comprehensive instrument for the assessment of direct care activities. The RUD comprises three domains - basic ADL, instrumental ADL, and supervision - and time is registered in hours and minutes during an ordinary day with a time frame working backwards from the last week. The Swedish version of the RUD has shown satisfactory estimates of reliability and construct validity in both on formal and informal care settings [55-58].

\section{Health related quality of life (EQ-5D)}

The EQ-5D is a generic quality of life and health status instrument designed by the EuroQoL group. The EQ-5D comprises five dimensions - mobility, self-care, usual activities, pain/discomfort, and anxiety/depression. Each dimension has three levels of perceived problems: $1=$ no problems, $2=$ some problems, and $3=$ severe problems. The EQ-5D index scores were calculated using preference scores generated from a population using the EQ-5D-5L_ Crosswalk_Index_Value_Calculator.v2 (Value Health, 2012) using the Danish tariff because Swedish values have not been calculated. This tariff was used to calculate a utility index for each resident. EQ-5D index scores range from 0 to 1 , where 0 indicates the worst possible health state and 1 indicates the best possible health state.

\section{Data analysis}

The IBM SPSS statistics version 25 was used to analyse the data. The scale distribution and normality of the scales were tested through measures of skewness, Kolmogorov-Smirnov analysis, and visual examination of the histograms. Missing items in the P-CAT were replaced with the mean values of the individual for the total scale, and up to two missing items were replaced $(<8 \%)$. For the two subscales of the DCSQ, only one item was replaced - Psychological Demands $(<3.4 \%)$ or Decision Latitude $(<2.2 \%)$ (cf. 56). No violations of the prerequisites for linear regression concerning multicollinearity normality, linearity, or homoscedasticity of residuals were detected (cf. Pallant 2013, p. 164). A P-value < 0.05 was considered statistically significant. All analyses of PCC were based on an aggregated unit-level score (mean value for the unit), while all resident and staff variables were based on individual scores.

First, descriptive statistics were used for background characteristics of staff and residents. Second, Pearson's product-moment correlation was used to explore the correlation between PCC, staff job strain, quality of life, resident quality of life, and resource use. Third, a multiple linear regression analysis was conducted to explore the relationship between PCC, staff job strain, resident quality of life, and resource use. The model was adjusted for resident cognitive status, age, dependence in ADL, and sex.

\section{Results \\ Characteristics of the sample}

The sample of 3605 staff had a mean age of 46.6 years (SD 11.3 years) and comprised mostly women (95.3\%). The most common qualification among staff was enrolled nurse (82.5\%), and the average length of work experience in the nursing home was 9.9 years (SD 8.0 years) (see Table 1).

The sample of 4831 residents had a mean age of 85.5 years (SD 7.8 years) and comprised mostly women (67.8\%). Most residents were ADL dependent (84\%) and cognitively impaired (66.6\%). The majority of residents resided in general units (62.2\%) (see Table 2). The mean time for proxy raters (staff) knowing the resident was 3.6 years.

\section{Relationship of PCC with resource use, quality of life, and job strain}

No correlation was found between PCC and resource use $(r=-0.0 .45, p=0.10)$. There was a significant positive correlation between PCC and quality of life $(r=$ $0.106, p<0.000)$ and a significant negative correlation $(r=-0.423, p<0.001)$ between PCC and job strain. The

Table 1 Background characteristics of staff $n=3605$

\begin{tabular}{lll}
\hline & $\mathbf{n}^{\mathbf{a}}$ (\%) & $\mathbf{m}$ (SD) \\
\hline Age (Years) & & $46.6(11.3)$ \\
Sex & $167(4.7)$ & \\
Men & $3401(94.3)$ & \\
Women & $37(1.0)$ & \\
Did not state & & \\
Qualifications & $12(0.3)$ & \\
Registered nurses & $2918(80.9)$ & \\
Enrolled nurses & $463(12.8)$ & \\
Nurse's assistants & $82(2.3)$ & \\
No formal qualifications & $60(1.7)$ & \\
Other education & $70(1.9)$ & \\
Did not state & \\
Years of experience in aged care & \\
Years in this nursing home unit & \\
Day/night staff & & \\
Day shift & $80(2.2)$ \\
Day and evening & $3140(87.1)$ \\
Day, evening, night shift & $318(8.8)$ \\
Did not state & $67(1.9)$ & \\
\hline
\end{tabular}

${ }^{a}$ Missing data on age for 76 persons

${ }^{\mathrm{b}}$ Missing data on 132 persons

c Missing data on 209 persons 
Table 2 Demographics of residents $n=4831$

\begin{tabular}{|c|c|c|}
\hline & $\mathrm{n}(\%)^{\mathrm{a}}$ & $\mathrm{m}(\mathrm{SD})$ \\
\hline Age (Years) & & $85.5(7.8)^{b}$ \\
\hline \multicolumn{3}{|l|}{ Sex } \\
\hline Men & 1538 (31.8) & \\
\hline Women & $3239(67.0)$ & \\
\hline Missing data & $54(1.1)$ & \\
\hline \multicolumn{3}{|l|}{ ADL Capacity } \\
\hline Independent & $716(14.8)$ & \\
\hline Dependent & $3768(78.0)$ & \\
\hline Missing data & $347(7.2)$ & \\
\hline \multicolumn{3}{|l|}{ Cognitive impairment } \\
\hline Yes & $2827(58.2)$ & \\
\hline No & $1418(29.4)$ & \\
\hline Missing data & $586(12.1)$ & \\
\hline Residing in SCU & $1778(37.8)$ & \\
\hline Residing in general units & $2931(60.7)$ & \\
\hline Missing data & $122(2.5)$ & \\
\hline Length of stay in months & & $30.5(33.1)$ \\
\hline
\end{tabular}

${ }^{2} \%$ does not always add up to 100 in all variables due to roundings'

${ }^{\mathrm{b}}$ Missing data on age for 704 persons

mean values and correlations between all study variables are shown in Table 3.

The multiple linear regression analysis constructed with PCC as the dependent variable showed that a higher degree of PCC was not significantly related to higher resource use (standardised $\beta=0.031, p<0.129$ ). A higher degree of PCC was significantly related to higher quality of life among residents (standardised $\beta=0.042$, $p<0.028$ ). Furthermore, a higher degree of PCC was also significantly related to a lower level of perceived job strain among staff (standardised $\beta=-0.53, p<0.001$ ). This model explained $35.3 \%$ of the variance of PCC (Table 4).

\section{Discussion}

The aim of this study was to explore PCC and its association with resource use, resident quality of life, and staff job strain. The findings indicate that increased PCC provision was not related to increased resource use, but a higher degree of PCC was related to higher resident quality of life and to lower staff job strain.

A reasonable interpretation of these results is that PCC provision does not require increased care hours for nursing home providers once PCC has been implemented and that many nursing interventions do not require more resources even though they are performed in a more person-centred manner. For example, it takes as much effort to apply cream to an elderly lady's back in a way that makes her feel like a queen as it does to just apply the cream without reflecting on how it is done.

In Sweden, PCC is recommended by the National Board of Health and Welfare (NBHW) [10]. The NBHW estimated that PCC would increase the need for resources in Swedish elderly care when training for and implementing PCC, a cost increase that has been confirmed in previous intervention research [22]. The NBHW [10] also estimated that the increased costs will be maintained over time because the provision of PCC is expected to increase the need for resources also in the long run [10]. However, this does not seem to hold true because PCC was not related to changes in resource use in the current study. A study based on the same sample as the current study showed that caring for residents with ADL dependency and cognitive impairment was related to increased resource use [59], indicating that this study population is already associated with high resource use. The findings of the current study showed that highquality PCC does not need extended resources, which suggests that PCC might be provided within prevailing elderly care budgets. Estimating resource use in nursing homes has seldom been performed because Swedish elderly care has always offered an all-inclusive concept, but our previous study reported this thoroughly [59]. This situation will probably remain the same, but nevertheless it is important to clarify whether the "gold standard" of nursing home care, PCC, influences resource use. This study provides a small but seemingly important piece to the puzzle because it targets the WHO's recommendation of PCC as a global strategy by exploring whether PCC as the model of care is still viable during times of restricted resources and when facing future challenges.

The data also showed that higher PCC was associated with higher resident quality of life, which is supported

Table 3 Mean values and correlations of study variables

\begin{tabular}{|c|c|c|c|c|c|}
\hline & $\mathbf{N}$ & $M(s d)$ & $r$ & $r$ & $r$ \\
\hline & & & PCC (P-CAT) & Resource use (RUD) & HRQoL (EQ5D) \\
\hline PCC (P-CAT) & 3554 & $50.0(7.4)$ & & & \\
\hline Resource use (RUD) & 2360 & $40.7(37.4)$ & 0.029 & & \\
\hline HRQoL (EQ5D) & 3062 & $0.70(0.08)$ & $0.065^{b}$ & $-0.45^{\mathrm{a}}$ & \\
\hline Job Strain (DCSQ) & 3482 & $0.71(0.17)$ & $-0.563^{b}$ & -0.023 & $-0.66^{\mathrm{b}}$ \\
\hline
\end{tabular}

${ }^{a}$ Correlation is significant at the 0.05 level (2-tailed). ${ }^{\mathrm{b}}$ Correlation is significant at the 0.01 level (2-tailed) 
Table 4 Multiple linear regression model explaining the variance of person centred care ${ }^{a, b}$

\begin{tabular}{lllll}
\hline $\begin{array}{l}\text { Independent } \\
\text { variables }\end{array}$ & \multicolumn{2}{l}{ Unstandardised Coefficients } & & \multicolumn{1}{l}{$\begin{array}{l}\text { Standardised } \\
\text { Coefficients }\end{array}$} \\
\cline { 2 - 4 } & $\boldsymbol{\beta}$ & Std.Error & $\boldsymbol{p}$ St. $\boldsymbol{\beta}$ \\
\hline HRQOL (EQ5D) & 3.620 & 1.648 & 0.042 & 0.028 \\
Resource Use & 0.007 & 0.004 & 0.031 & 0.129 \\
Job strain (staff) & -22.733 & 0.837 & -0.525 & 0.000 \\
\hline
\end{tabular}

Dependent Variable: Person-centred care (P-CAT)

Adjusted R Square 0.35

${ }^{a}$ Model adjusted for potential confounders (resident age, sex, physical function (ADL) and resident cognitive status)

${ }^{\mathrm{b}} \mathrm{N}$ for joint analysis 1787 persons due to missing values

by previous cross-sectional and intervention studies [21, $23,24]$. Although quality of life is not a measure of quality of care per se, it might serve as a proxy in this sense. One reasonable interpretation is that when staff are working in a person-centred manner, which includes supporting resident autonomy, this enhances residents' independence and autonomy in terms of mobility, selfcare, and usual activities, all of which are aspects that contribute to high quality of life. This might imply that efforts can be made to maintain autonomy while also preventing functional dependency of this frail population by providing care based on a person-centred philosophy. However, because contradictory findings have also been reported in intervention studies with no significant changes from PCC on quality of life among residents [25-27], the relationship between PCC and quality of life seems complex and further studies are recommended. Further, the association, although statistically significant, might be of limited clinical importance due to the weakness of the association.

The nursing home work environment have long been known to be inherently stressful and demanding for staff who daily confronts a variety of job stressors with high risk of job strain as result [34, 36-38] Experiencing job strain has been related to increased risk for other negative health effects, such as; headaches, insomnia, poor concentration, irritability and nervousness [42, 43] and also sleeping problem [40], Other studies have suggested that staff who do not have the resources needed, or who are unable to provide the care they desire to, are also at risk for strain and burnout $[37,59]$. Mitigating the perception of job strain is therefore crucial to protect staff health and wellbeing and consequently resident health and well-being [59]. Previous studies have also shown decreased stress and strain among staff when working in a person-centred manner $[45-47,49]$ and a higher level of PCC was also empirically related to lower perception of staff job strain in this current study.This study confirms these international findings by reporting strong associations between job strain and PCC. The theoretical assumption of job strain postulates that when the content of the work is too extensive in relation to the time available, with little or no opportunities to decide what, when, or how the work will be performed, staff are at risk of suffering from undo strain [33]. A reasonable interpretation of our findings is that staff, in line with a person-centred philosophy, are encouraged to initiate, become involved in, and take ownership of care provision, thus having the opportunity to organise the content and structure of care themselves. This might enable a balance between demands and control in daily practice with reduced job strain as a result.

A previous review [60] has also reported that working in a person-centred manner also improves job satisfaction, and reduces turnover in addition to reduction of stress, which ultimately may influence the quality of care provided giving further implications. Job strain can be seen as a measure of quality of work life and previous research has suggested the quality of work life must be one of the highest prioritised goals of the institutions, due to its major impact on care standards [61]. Addressing staff stress and strain seems therefor crucial given the major impact this has on the care organisation, staff and resident health, and the care that is provided [62]. The findings of this study thus suggest that PCC might be one plausible way to reduce the experience of job strain in nursing homes, thus having implications for care providers.

The levels of PCC within this sample of nationwide data are consistent with previous measures of PCC (measured with the P-CAT) in Swedish nursing home care [49], but slightly higher than international nursing home studies that have used the P-CAT $[20,63,64]$. Because the results of this study are part of a larger project with a longitudinal design, these could be of value as a point of reference for future national and international research studies.

\section{Methodological considerations}

The cross-sectional design of this study comes with limitations because the causal direction of these findings cannot be established. Longitudinal and interventional designs are therefore needed to further investigate causality. In this study, the assessment of residents was made 
by staff through proxy ratings, which might be less than ideal but can be, as in this case, the only solution when including participants with a high prevalence of cognitive impairments [65]. However, in this study the proxies had known the older person for a fairly long time, implying good knowledge of the resident being assessed. Another limitation of the study is that it is based on the Swedish elderly care system, which might differ from international organisational conditions and thereby affect the study's generalisability. Nevertheless, because this study draws on extensive randomised data from a national sample of Swedish nursing homes, it seems reasonable to argue that the findings can be applied across different contexts and settings. All instruments have been checked for normality, and only the RUD data were slightly skewed, but linear regression is still considered to be robust as long as no violations to the assumptions of residuals exist, which is the case in our data [66]. For the joint regression analysis the number of analysable persons are quite smaller than the total number of persons included in the study. This might of course introduce selection bias and the results should be interpreted with sound caution.

\section{Conclusion}

To conclude, PCC does not increase resource utilisation, but positively impacts resident quality of life and alleviates the care burden in terms of job strain among staff. It also seems reasonable to conclude that providing PCC can be seen not only as a societal investment, but also as a strategy to sustain and improve wellbeing among nursing home residents and staff.

\section{Abbreviations}

ADL: Activities of Daily Living; DCSQ: The Swedish Demand-Control-Support Questionnaire; EQ-5D: EuroQoL Health Related Quality of Life; P-CAT: Personcentred Care Assessment Tool; PCC: Person Centred Care; RUD: Resource Utilization in Dementia; SWENIS: The Swedish National Inventory of Care and Health in Residential Aged Care

\section{Acknowledgements}

Our thanks the nursing home managers for their cooperation and all the staff who took the time to fill in the questionnaires. Parts of this work has been published as an abstract and poster in the Program Abstracts from the GSA 2019 Annual Scientific Meeting "Strength in Age-Harnessing the Power of Networks" [67].

\section{Authors' contributions}

$A S$ and $A B$ were responsible for the study concept and design. $A B$ and the SWENIS research team collected the data. AS carried out the statistical analyses with help from $A B$. AS, AB, and POS interpreted the data and prepared the manuscript. All authors critically revised the manuscript, added their comments, and approved the final version.

\section{Funding}

This study was supported by grants from the Swedish Research Council for Health, Working life and Welfare (2014-4016) and the Swedish Research Council (521-2014-2715). The funding organisations had no role in the design or execution of the study, in the collection, analysis, or interpretation of the data, or in the preparation, review, or approval of the submitted manuscript. Open Access funding provided by University of Umea.

\section{Availability of data and materials}

The dataset supporting this article and its conclusions cannot be shared because informed consent has not been obtained for this.

\section{Ethics approval and consent to participate}

Ethical approval for this study was received from the Regional Ethical Review Board in Umeå, Sweden (Dnr 2013-269-31).

\section{Consent for publication}

Not applicable.

\section{Competing interests}

Not applicable.

\section{Author details}

'Department of Nursing, Umeå University, Vårdvetarhuset, 90187 Umeå, Sweden. ${ }^{2}$ Division of Neurogeriatrics, Karolinska Institutet, Huddinge, Sweden. ${ }^{3}$ NVS, Department of Nursing, Karolinska Institutet, Huddinge, Sweden.

Received: 20 February 2020 Accepted: 28 October 2020

Published online: 11 November 2020

\section{References}

1. Partridge L, Deelen J, Slagboom PE. Facing up to the global challenges of ageing. Nature. 2018;561(7721):45-56. https://doi.org/10.1038/s41586-0180457-8 Epub 2018 Sep 5. PMID: 30185958.2

2. Lagergren M. Whither care of older persons in Sweden?--a prospective analysis based upon simulation model calculations, 2000-2030. Health Policy. 2005;74(3):325-34.

3. Swedish Institute. Facts about Sweden - Elderly care. https://sweden.se/wpcontent/uploads/2013/11/Elderly-care-low-resolution.pdf. Accessed 11 Jan 2020 .

4. Bjork S, Juthberg C, Lindkvist M, Wimo A, Sandman PO, Winblad B, et al Exploring the prevalence and variance of cognitive impairment, pain, neuropsychiatric symptoms and ADL dependency among persons living in nursing homes; a cross-sectional study. BMC Geriatr. 2016;16:154..

5. Helvik AS, Engedal K, Benth Jك̌, Selbæk G. Prevalence and severity of dementia in nursing home residents. Dement Geriatr Cogn Disord. 2015; 40(3-4):166-77.

6. Seitz D, Purandare N, Conn D. Prevalence of psychiatric disorders among older adults in long-term care homes: a systematic review. Int Psychogeriatr. 2010;22(7):1025-39.

7. Fratiglioni L, Ding M, Santoni G, Berglund J, Elmståhl S, Fagerstrom C, et al. Demensförekomst i Sverige: geografiska och tidsmässiga trender 2001-2013 - Resultat från den svenska nationella studien om åldrande, vård och omsorg - SNAC. 2017

8. Swedish Institute. Facts about Sweden - Elderly care2013 11/09/2017.

9. Lagergren M. The systems of care for frail elderly persons: the case of Sweden. Aging Clin Exp Res. 2002;14(4):252-7.

10. The Swedish National Board of Health and Welfare. Nationella riktlinjer för vård och omsorg vid demenssjukdom- Stöd för styrning och ledningremissversion (in Swedish). 2017 http://www.socialstyrelsen.se/ publikationer2017/2017-12-2: Accessed 20 Jan 2020.

11. U.S. Department of Health and Human Services. National Strategy for Quality Improvement in Health Care: Agency-Specific Quality Strategic Plans. 2010 [Available from: https://www.google.se/url?sa=t\&rct=j\&q=\&esrc= s\&source $=$ web\&cd $=2 \&$ ved $=2$ ahUKEwjShc-1-5 TgAhUwpYsKHZFoCtEQFjABegQICRAC\&url=https\%3A\%2F\%2Fwww.ahrq gov\%2Fsites\%2Fdefault\%2Ffiles\%2Fwysiwyg\%2Fworkingforquality\%2 Fnqsplans.pdf\&usg=AOvVaw3196QNv4q_mZbR8hIJhIUp. Accessed 20 Jan 2020

12. WHO. Global strategy on people-centred and integrated health services: An overview of evidence. 2015.

13. Edvardsson D, Winblad B, Sandman PO. Person-centred care of people with severe Alzheimer's disease: current status and ways forward. Lancet Neurol. 2008;7(4):362-7

14. Dewing J. Concerns relating to the application of frameworks to promote person-centredness in nursing with older people. J Clin Nurs. 2004;13(3a):39-44

15. Epp T. Person-centred dementia care: a vision to be refined. Can Alzheimer Dis Rev. 2003;5(3):14-9. 
16. McCormack B, Dewing J, McCance T. Developing person-centred care: addressing contextual challenges through practice development. Online J Issues Nurs. 2011;16(2):3.

17. Brooker D. What is person-centred care in dementia? Rev Clin Gerontol. 2004;13(3):215-22.

18. McCormack B. Person-centredness in gerontological nursing: an overview of the literature. J Clin Nurs. 2004;13(3a):31-8

19. McCormack B, McCance TV. Development of a framework for personcentred nursing. J Adv Nurs. 2006;56(5):472-9.

20. Edvardsson D, Innes A. Measuring person-centered care: a critical comparative review of published tools. Gerontologist. 2010;50(6):834-46.

21. Rokstad AM, Rosvik J, Kirkevold O, Selbaek G, Saltyte Benth J, Engedal K. The effect of person-centred dementia care to prevent agitation and other neuropsychiatric symptoms and enhance quality of life in nursing home patients: a 10-month randomized controlled trial. Dement Geriatr Cogn Disord. 2013;36(5-6):340-53.

22. Chenoweth L, King MT, Jeon $\mathrm{YH}$, Brodaty $\mathrm{H}$, Stein-Parbury J, Norman R, et al. Caring for aged dementia care resident study (CADRES) of person-centred care, dementia-care mapping, and usual care in dementia: a clusterrandomised trial. Lancet Neurol. 2009;8(4):317-25.

23. Sjogren K, Lindkvist M, Sandman PO, Zingmark K, Edvardsson D. Personcentredness and its association with resident well-being in dementia care units. J Adv Nurs. 2013:69(10):2196-205.

24. Terada S, Oshima E, Yokota O, Ikeda C, Nagao S, Takeda N, et al. Personcentered care and quality of life of patients with dementia in long-term care facilities. Psychiatry Res. 2013;205(1-2):103-8.

25. Fossey J, Ballard C, Juszczak E, James I, Alder N, Jacoby R, et al. Effect of enhanced psychosocial care on antipsychotic use in nursing home residents with severe dementia: cluster randomised trial. BMJ. 2006; 332(7544):756-61.

26. Chenoweth L, Forbes I, Fleming R, King MT, Stein-Parbury J, Luscombe G, et al. PerCEN: a cluster randomized controlled trial of person-centered residential care and environment for people with dementia. Int Psychogeriatr. 2014;26(7):1147-60.

27. Dichter MN, Quasdorf T, Schwab CG, Trutschel D, Haastert B, Riesner C, et al Dementia care mapping: effects on residents' quality of life and challenging behavior in German nursing homes. A quasi-experimental trial. Int Psychogeriatr. 2015;27(11):1875-92.

28. Chenoweth L, Stein-Parbury J, Lapkin S, Wang A, Liu Z, Williams A. Effects of person-centered care at the organisational-level for people with dementia. A systematic review. PloS one. 2019;14(2):e0212686.

29. Wimo A, Guerchet M, Ali GC, Wu YT, Prina AM, Winblad B, et al. The worldwide costs of dementia 2015 and comparisons with 2010. Alzheimers Dement. 2017;13(1):1-7.

30. Caspar S, Cooke HA, O'Rourke N, MacDonald SW. Influence of individual and contextual characteristics on the provision of individualized care in longterm care facilities. Gerontologist. 2013;53(5):790-800.

31. Kontos PC, Mitchell GJ, Mistry B, Ballon B. Using drama to improve personcentred dementia care. Int J Older People Nursing. 2010;5(2):159-68.

32. Palese A, Granzotto D, Broll MG, Carlesso N. From health organizationcentred standardization work process to a personhood-centred care process in an Italian nursing home: effectiveness on bowel elimination model. Int J Older People Nursing. 2010;5(2):179-87.

33. Karasek R. In: Theorell T, editor. Healthy work : stress, productivity, and the reconstruction of working life. New York, N.Y: New York, N.Y. : Basic Books; 1990.

34. Edvardsson D, Sandman PO, Nay R, Karlsson S. Predictors of job strain in residential dementia care nursing staff. J Nurs Manag. 2009;17(1):59-65.

35. Hasson $\mathrm{H}$, Arnetz JE. Nursing staff competence, work strain, stress and satisfaction in elderly care: a comparison of home-based care and nursing homes. J Clin Nurs. 2008;17(4):468-81.

36. te Boekhorst S, Willemse B, Depla MF, Eefsting JA, Pot AM. Working in group living homes for older people with dementia: the effects on job satisfaction and burnout and the role of job characteristics. Int Psychogeriatr. 2008;20(5):927-40.

37. Schmidt $\mathrm{KH}$. The relation of goal incongruence and self-control demands to indicators of job strain among elderly care nursing staff: a cross-sectional survey study combined with longitudinally assessed absence measures. Int J Nurs Stud. 2010;47(7):855-63.

38. Edberg AK, Bird M, Richards DA, Woods R, Keeley P, Davis-Quarrell V. Strain in nursing care of people with dementia: nurses' experience in Australia, Sweden and United Kingdom. Aging Ment Health. 2008;12(2):236-43.
39. Morgan DG, Semchuk KM, Stewart NJ, D'Arcy C. Job strain among staff of rural nursing homes. A comparison of nurses, aides, and activity workers. J Nurs Adm. 2002;32(3):152-61.

40. Elovainio M, Heponiemi T, Kuusio $H$, Jokela M, Aalto AM, Pekkarinen L, et al. Job demands and job strain as risk factors for employee wellbeing in elderly care: an instrumental-variables analysis. Eur J Pub Health. 2015;25(1):103-8.

41. Pekkarinen L, Elovainio M, Sinervo T, Heponiemi T, Aalto AM, Noro A, et al. Job demands and musculoskeletal symptoms among female geriatric nurses: the moderating role of psychosocial resources. J Occup Health Psychol. 2013;18(2):211-9.

42. Schmidt KH, Diestel S. Differential effects of decision latitude and control on the job demands-strain relationship: a cross-sectional survey study among elderly care nursing staff. Int J Nurs Stud. 2011;48(3):307-17.

43. Schmidt KH, Diestel S. Job demands and personal resources in their relations to indicators of job strain among nurses for older people. J Adv Nurs. 2013:69(10):2185-95.

44. Maslach C. JSLM. Maslach Burnout Inventory Manual. Palo Alto: Consulting Psychologist Press; 1996

45. Jeon YH, Luscombe G, Chenoweth L, Stein-Parbury J, Brodaty H, King $M$, et al. Staff outcomes from the caring for aged dementia care resident study (CADRES): a cluster randomised trial. Int J Nurs Stud. 2012:49(5):508-18.

46. Dilley L, GL. Staff perspectives on person-centered care in practice. Alzheimer's Care Today. 2010;11(3):172-85..

47. van den Pol-Grevelink A, Jukema JS, Smits CH. Person-centred care and job satisfaction of caregivers in nursing homes: a systematic review of the impact of different forms of person-centred care on various dimensions of job satisfaction. Int J Geriatr Psychiatry. 2012;27(3):219-29..

48. Hunter PV, Hadjistavropoulos T, Thorpe L, Lix LM, Malloy DC. The influence of individual and organizational factors on person-centred dementia care. Aging Ment Health. 2016;20(7):700-8.

49. Sjogren $K$, Lindkvist M, Sandman PO, Zingmark K, Edvardsson D. To what extent is the work environment of staff related to person-centred care? A cross-sectional study of residential aged care. J Clin Nurs. 2015;24(9-10): 1310-9.

50. Katz S, Ford AB, Moskowitz RB, Jackson BA, Jaffe MW. A standardized measure of biological and psychosocial function. JAMA. 1963:185:914-9.

51. Gottfries CG. IG. Psykogeriatriskt skattningsschema. St. Lars Hospital: Lund; 1968

52. Edvardsson D, Fetherstonhaugh D, Nay R, Gibson S. Development and initial testing of the person-centered care assessment tool (P-CAT). Int Psychogeriatr. 2010;22(1):101-8.

53. Sjogren $K$, Lindkvist M, Sandman PO, Zingmark K, Edvardsson D. Psychometric evaluation of the Swedish version of the person-centered care assessment tool (P-CAT). Int Psychogeriatr. 2012;24(3):406-15.

54. Wimo A, Wetterholm AL, Mastey $V$, Winblad B. Evaluation of the resource utilization and caregiver time in anti-dementia drug trials - a quantitative battery. In: Wimo A, Jonsson B, Karlsson G, Winblad B, editors. The health Economis of dementia. London: Wiley; 1998. p. 465-99.

55. Wimo A, Nordberg G, Jansson W, Grafstrom M. Assessment of informal services to demented people with the RUD instrument. Int J Geriatr Psychiatry. 2000;15(10):969-71.

56. Wimo A, Nordberg G. Validity and reliability of assessments of time. Comparisons of direct observations and estimates of time by the use of the resourceutilization in dementia (RUD)-instrument. Arch Gerontol Geriatr. 2007:44(1):71-81. https://doi.org/10.1016/j.archger.2006.03.001. Epub 2006 Jun 13.

57. Wimo A, Jonsson $L$, Zbrozek $A$. The resource utilization in dementia (RUD) instrument is valid for assessing informal care time in community-living patients with dementia. J Nutr Health Aging. 2010;14(8):685-90.

58. Wimo A, Gustavsson A, Jonsson L, Winblad B, Hsu MA, Gannon B. Application of resource utilization in dementia (RUD) instrument in a global setting. Alzheimers Dement. 2013:9(4):429-35 e17.

59. Juthberg C, Eriksson S, Norberg A, Sundin K. Perceptions of conscience, stress of conscience and burnout among nursing staff in residential elder care. J Adv Nurs. 2010;66(8):1708-18.

60. Rajamohan S, Porock D, Chang YP. Understanding the Relationship Between Staff and Job Satisfaction, Stress, Turnover, and Staff Outcomes in the Person-Centered Care Nursing Home Arena. J Nursing Scholarship. 2019; 51(5):560-8 
61. Vidal-Blanco G, Oliver A, Galiana L, Sansó N. Quality of work life and self-care in nursing staff with high emotional demand. Enferm Clin. 2019;29(3):18694. https://doi.org/10.1016/j.enfcli.2018.06.004 Epub 2018 Aug 28. PMID: 30170737. English, Spanish.

62. Hayes LJ, O'Brien-Pallas L, Duffield C, Shamian J, Buchan J, Hughes F, et al. Nurse turnover: a literature review - an update. Int J Nurs Stud. 2012;49(7): 887-905.

63. Rokstad AM, Engedal K, Edvardsson D, Selbaek G. Psychometric evaluation of the Norwegian version of the person-centred care assessment tool. Int J Nurs Pract. 2012;18(1):99-105.

64. Martinez T, Suarez-Alvarez J, Yanguas J, Muniz J. Spanish validation of the person-centered care assessment tool (P-CAT). Aging Ment Health. 2016; 20(5):550-8.

65. Logsdon RG, Gibbons LE, McCurry SM, Teri L. Assessing quality of life in older adults with cognitive impairment. Psychosom Med. 2002;64(3):510-9.

66. Schmidt AF, Finan C. Linear regression and the normality assumption. J Clin Epidemiol. 2018;98:146-51.

67. Backman A, Sköldunger A. Person-centered care related to resource use, resident quality of life, and staff job strain in Swedish nursing homes. Innovation in Aging. 2019;3(Supplement_1):S36.

\section{Publisher's Note}

Springer Nature remains neutral with regard to jurisdictional claims in published maps and institutional affiliations.

Ready to submit your research? Choose BMC and benefit from:

- fast, convenient online submission

- thorough peer review by experienced researchers in your field

- rapid publication on acceptance

- support for research data, including large and complex data types

- gold Open Access which fosters wider collaboration and increased citations

- maximum visibility for your research: over $100 \mathrm{M}$ website views per year

At BMC, research is always in progress.

Learn more biomedcentral.com/submissions 